\title{
The Fragility Index in HIV/AIDS Trials
}

\author{
J Gen Intern Med 35(7):2204 \\ DOI: $10.1007 / \mathrm{s} 11606-019-05554-\mathrm{x}$ \\ (c) Society of General Internal Medicine 2019
}

Robert S. Van Howe, MD, MS, FAAP

Department of Pediatrics and Human Development, Michigan State University College of Human Medicine, Marquette, MI, USA differential bias.
$\mathrm{D}$

ear Editor:

The recent report by Wayant and colleagues on the fragility index ${ }^{1}$ did not include the African randomized clinical trials on HIV and adult male circumcision. ${ }^{2-4}$ Analysis of these trials may provide insight into the interaction between $p$ values and fragility in overpowered studies. The three trials shared nearly identical methodologies, the same sources of differential bias (lead-time bias, attrition bias, selection bias, and confirmation bias), and nearly identical results. All three trials were powered to demonstrate an absolute risk reduction of $1 \%$. All three were discontinued prematurely following interim analyses that satisfied pre-established early termination criteria.

Of interest, the fragility index for the three trials were 4,5 , and 6 for the Ugandan, ${ }^{2}$ Kenyan, ${ }^{3}$ and South African ${ }^{4}$ trials, respectively. This suggests that 4 to 6 patients with an event changed to a nonevent would nullify the study's statistical significance. The fragility quotient for the trials were 0.0008 , 0.0018 , and 0.0018 , respectively, suggesting that changes in between 1 and 2 patients per 1000 would likewise nullify the study's statistical significance. In the three trials, 205 participants seroconverted, while 700 were lost to follow-up. The men who seroconverted were assumed to have acquired their HIV infections through heterosexual transmission although the investigators made no attempt to confirm the source of infection. Applying the Cochran "risk of bias" tool 2.0, these trials are at "high risk" for bias.

The lack of robustness exhibited by these trials raises both statistical and policy concerns. Despite their fragility, these overpowered studies were able to generate small enough $p$ values to trigger early termination using standard statistical criteria.

This highlights an important caveat when interpreting the results of trials powered to demonstrate small absolute differences: it is difficult to differentiate true signal from noise and to differentiate any treatment effect from the influence of

On the policy level, millions of dollars have been expended to roll out male circumcision as a primary preventive for HIV in African men. This policy was hastily adopted by the World Health Organization primarily based on these fragile trials. ${ }^{5}$ The impact of the rollout is unknown, with some countries showing an increase in HIV incidence following the rollout. ${ }^{6}$

The fragility index and quotient need to be applied to the results of all randomized clinical trials as they can help identify the weaknesses of overpowered trials.

Corresponding Author: Robert S. Van Howe, MD, MS, FAAP; Department of Pediatrics and Human Development Michigan State University College of Human Medicine, 413 E. Ohio Street, Marquette, MI 49855, USA (e-mail: rsvanhowe@att.net).

\section{Compliance with ethical standards:}

Conflict of Interest: The author declares that he has no conflict of interest.

\section{REFERENCES}

1. Wayant C, Meyer C, Gupton R, Som M, Baker D, Vassar M. The fragility index in a cohort of HIV/AIDS randomized controlled trials. J Gen Intern Med 2019; epub ahead of print.

2. Gray RH, Kigozi G, Serwadda D, et al. Male circumcision for HIV prevention in men in Rakai, Uganda: a randomised trial. Lancet. 2007;369:657-66.

3. Bailey RC, Moses S, Parker CB, et al. Male circumcision for HIV prevention in young men in Kisumu, Kenya: a randomised controlled trial. Lancet. 2007;369:643-56.

4. Auvert B, Taljaard D, Lagarde E, Sobngwi-Tambekou J, Sitta R, Puren A. Randomized, controlled intervention trial of male circumcision for reduction of HIV infection risk: The ANRS 1265 Trial. PLoS Med. 2005;2(11):e298.

5. Giami A, Perrey C, de Oliveria Mendonça AL, de Camargo KR. Hybrid forum or network? the social and political construction of an international 'technical consultation': male circumcision and HIV prevention. Glob Publ Health. 2015; 10:589-606.

6. More on rise of HIV prevalence rate in Mozambique. Club of Mozambique. May 11, 2017. Available at: https://clubofmozambique.com/news/moreon-rise-of-hiv-prevalence-rate-in-mozambique/. Accessed May 31, 2019.

Publisher's Note Springer Nature remains neutral with regard to jurisdictional claims in published maps and institutional affiliations.

Received June 18, 2019

Accepted November 7, 2019

Published online November 25, 2019 